\title{
Temas Emergentes em Gestão e Políticas Públicas: Tendências Gerais ${ }^{1}$
}

Marta Ferreira Santos Farah ${ }^{2}$

RESUMO: A experiência recente de governos locais no Brasil caracteriza-se pela presença de inovações no plano da gestão e das políticas públicas. A reflexão sobre esta experiência permite identificar temas de análise relevantes para o campo de estudos de governos locais, alguns dos quais já integrados pela literatura, outros ainda não explorados.

Mesmo temas já abordados, requerem, por outro lado, novas abordagens e perspectivas analíticas. Este trabalho tem por objetivo identificar, a partir da análise de políticas e programas promovidos por governos locais no período recente, temas de investigação relevantes, trazidos pela própria prática. Dentre estes temas, incluem-se gênero e políticas públicas; geração de emprego e renda, gestão ambiental; racionalização de gastos e aumento de arrecadação municipal; transparência e controle da gestão pública; novos arranjos institucionais, dentre outros. Mas, a ausência de políticas e a "omissão” do Estado em determinadas áreas também apontam para temas emergentes. Dentre os temas em que a ação estatal ainda é incipiente ou mesmo inexistente, incluem-se juventude e raça. Outra lacuna decorre da tradição brasileira de identificação do Estado com o poder executivo. Assim é notável a ausência de ações inovadoras e de reflexão sobre o poder legislativo também no âmbito local de governo.

PALAVRAS CHAVE: Governo Local, Políticas Públicas , Inovações

ABSTRACT: The recent experience of the local level of government in Brazil is characterized by the presence of innovations in the field of management and public policies. The analysis of this experience makes it possible to identify issues relevant for the field of local government studies. Some of these issues have already been integrated in the literature but some of them have not been explored yet. The goal of this article is to identify areas of study that comes from the analysis of policies and programs promoted recently by local government. These areas include: gender, employment and income, environment management, rationality in public expenditure, accountability and new institutional arrangements. But, the lack of policies and the government absence in some areas also points to some relevant issues. Among these areas where the governmental action remains fragile are race and youth. The Brazilian executivist tradition - which identifies government with the executive branch - is responsible for another area very poor on innovations: there is a lack of innovative initiatives led by the legislative level.

KEYWORDS: Local Government, Public Policies, Innovations.

\footnotetext{
${ }^{1}$ Este artigo constitui uma versão revista e atualizada de trabalho apresentado no IX Colóquio Internacional sobre Poder Local, SalvadorBahia-Brasil, 16 a 18 de Junho de 2003

${ }^{2}$ Professora da FGV-EAESP, no Curso de Mestrado em Administração Pública e Governo. Pesquisadora do Centro de Administração Pública e Governo. Coordenadora do Curso de Graduação em Administração.Endereço para correspondência: Av. 9 de Julho 2029.11º andar. Cep-01313 902. Bela Vista São Paulo
} 


\section{Introdução}

O campo de estudos sobre governo local reúne contribuições de diversas disciplinas e "campos de estudo": da ciência política - e de um de seus subcampos o das políticas públicas; da administração - sobretudo da administração pública; da sociologia; do planejamento urbano, para mencionar alguns exemplos significativos. A incorporação de temas de investigação por este campo de estudos sofre, portanto, a influência de uma evolução interna a cada uma destas áreas ou disciplinas. Mas, a evolução dos temas de pesquisa sobre governo local reflete, por outro lado, a dinâmica social e política. Foi esta dinâmica mais abrangente que fez confluírem para a esfera local os olhares e as lentes de várias disciplinas a partir do final dos anos 70, à medida que se verificava uma reorientação descentralizante - seja no plano propositivo, seja no plano da ação - em diversos países

desenvolvidos e em desenvolvimento. É também a dinâmica social, com aspectos comuns a diversos países, mas com especificidades e singularidades regionais e locais, que explica em grande parte a incorporação de novos temas por este campo temático, a partir do interesse crescente pelo “local”, desde o início dos anos 80.

Dito de outra maneira, a agenda de pesquisas é influenciada por uma agenda de questões definida pela dinâmica social e política. No caso do campo de estudos de governo local, pode-se afirmar que a agenda de pesquisas é influenciada pela agenda pública que seleciona e prioriza "problemas relativos ao local e ao governo local”.

Como alguns autores demonstraram, ao analisar o processo de formação da agenda governamental, a existência de uma condição objetiva não é fator suficiente para colocar um tema na agenda pública. É necessário, primeiramente, que esta condição seja considerada um problema social, o que significa um problema para a sociedade (ou para segmentos ou grupos da sociedade) e, sobretudo, um problema que deve ser resolvido pela sociedade e pelos governos. Segundo Kingdon, é preciso distinguir, assim, uma “condição” e um “problema”:

“Há uma diferença entre uma condição e um problema. Nós nos deparamos com os mais diversos tipos de condições todos os dias, mas estas não assumem lugares centrais nas agendas políticas. Condições passam a ser definidas como problemas, e têm maiores chances de entrar na agenda, 
quando passamos a acreditar que deveríamos fazer algo para mudar tais condições” (KINGDON, 1995, p. 198).

\section{Tese semelhante é defendida por Fucks:}

“...a emergência de questões na agenda pública explica-se mais em termos da dinâmica social e política do que dos atributos intrínsecos dos assuntos em disputa, ou seja, das “condições reais” dos problemas em questão.

A condição para que uma determinada questão se torne objeto de atenção social é o seu reconhecimento como um assunto público”. (FUCKS, 2000, p. 80)

Os dois autores mencionados discutem os fatores responsáveis pela transformação de uma “condição”, situação ou questão em problema social, em objeto de atenção pública - por sua inclusão na agenda - atribuindo um importante papel a atores políticos, governamentais e não-governamentais. Fucks destaca neste processo a disputa tanto em torno das questões a serem incluídas na agenda, como no que diz respeito aos termos em que os problemas são definidos.

Finalmente, Kingdon distingue três tipos de agenda: a) a agenda sistêmica, que inclui a lista de assuntos que, segundo ele, são preocupação “do país”, sem contudo merecer a atenção do governo; b) a agenda governamental, que inclui os problemas que merecem a atenção do governo e c) a agenda de decisão, composta por um conjunto menor de problemas que são efetivamente objeto de decisão e de íticas governamentais (KINGDON, 1995, p. 202 e 206).

A respeito da agenda sistêmica ou agenda pública, é importante retomar a noção de disputa introduzida por Fucks. A agenda sistêmica resulta da disputa entre “agendas” de diferentes atores políticos - movimentos sociais, grupos profissionais, agentes governamentais etc.... Além disto, há variações regionais e locais e, quando se pensa no local e na constituição de agendas locais, é preciso também considerar a influência de atores inseridos em diferentes lugares - supra-locais e locais. Esta disputa e esta influência múltipla prossegue na passagem da agenda sistêmica para a governamental e para a agenda de decisão. Em relação às agendas de decisão de governos locais no Brasil atual, é preciso considerar, em 
particular, além dos atores locais, a influência de diretrizes e constrangimentos vindos do governo federal.

Retomando a questão central deste trabalho, relativa à agenda de pesquisas, é preciso considerar que a influência da dinâmica social e política se exerce tanto por meio da agenda governamental (e de decisão) como da agenda sistêmica, no sentido proposto por Kingdon. O presente trabalho procura discutir a emergência de temas de pesquisa no âmbito do campo de estudos de governo local no Brasil, à luz da experiência de governos locais nas últimas décadas. Concentra-se, portanto, na relação entre agenda de decisão e temas de pesquisa, uma vez que as iniciativas de governo assinalam a incorporação de temas da agenda sistêmica não apenas pela agenda governamental, mas pela agenda de decisão, o que significa que os governos não apenas passam a se preocupar com determinados temas, mas que tomam decisões em relação a tais temas e implementam políticas públicas e programas governamentais nestas áreas. No entanto, identifica também alguns temas emergentes que fazem parte do campo mais amplo da agenda pública ou sistêmica, “realimentados” em parte pela própria ação estatal ${ }^{3}$. A ação estatal constitui, ela própria, um dos elementos da “dinâmica social e política” que explica a constituição de um problema social, podendo evidenciar novos desafios e participar do "jogo político" de constituição (reconstituição) da agenda pública.

Ao destacar aqui as conexões entre agenda de pesquisa e a agenda pública e a governamental, tendo em vista a análise do campo de estudos de governo local, não se pretende defender quer um reflexo automático das agendas políticas sobre a de pesquisa, quer uma subordinação da pesquisa a uma racionalidade instrumental. De um lado, também na identificação e na seleção de temas relevantes de investigação interferem diversos fatores, incluindo condicionantes institucionais da própria área de pesquisa, assim como atores diversos, os quais também “disputam” prioridades.

De outro lado, no campo de estudos de governo local, é possível identificar dois eixos de investigação. Um primeiro eixo, de viés normativo, privilegia na pesquisa a obtenção de conhecimento como base para a ação, como subsídio para o governo, para a administração

\footnotetext{
${ }^{3}$ Como afirma Kingdon, "itens da agenda não surgem necessariamente em uma arena pública ou sistêmica mais abrangente, sendo então transferida para uma agenda governamental ou formal; de fato, o fluxo frequentemente ocorre no sentido contrário" (KINGDON, 1995, p. 206).
} 
pública, para políticas públicas e para movimentos sociais. Neste eixo repercutem de forma mais imediata a agenda pública relativa à problemática local e as agendas governamental e de decisão.

Um segundo eixo tem como preocupação central explicar a realidade, sem preocupação imediata com uma influência sobre a ação, enfatizando contribuições para avanços teóricos de determinada disciplina (ou campo de estudo), considerando a problemática local ${ }^{4}$. A “agenda” de temas de pesquisa neste caso é menos influenciada pela dinâmica da agenda política ou influenciada de forma mais indireta ${ }^{5}$. O avanço do campo se beneficiará, certamente, do diálogo entre estas duas perspectivas, a análise de casos orientada para a ação contribuindo para generalizações de caráter explicativo, o que, por sua vez, pode contribuir para o processo de tomada de decisões.

No que diz respeito à identificação de temas emergentes no campo de estudos de governo local, a partir da ação concreta de governos locais no Brasil, embora a própria fonte de reflexão destaque a orientação para a ação, questões de mais longo alcance - com repercussões teóricas potenciais - também podem ser identificadas.

\section{Inovações em governos locais e novos temas de pesquisa}

A democratização do país e a crise fiscal desencadearam, a partir dos anos 80, um processo de redefinição da intervenção do Estado no Brasil, no qual sobressai a crescente importância dos governos locais. A Constituição de 1988 constituiu um marco importante neste processo, introduzindo alterações no perfil do federalismo brasileiro que assinalam o início de um ciclo descentralizador, em que se destaca a transferência de recursos e encargos da União para os governos municipais.

A consolidação de um novo papel dos governos locais tem sido acompanhada, desde então, por um processo de construção de novas instituições e de novas práticas no nível municipal de governo. É neste sentido que se pode falar de um movimento de inovação na esfera

\footnotetext{
${ }^{4}$ A respeito de tensão entre estes dois tipos de abordagem, ver análise de Sabatier sobre a relação entre ciência política e o subcampo de políticas públicas nos Estados Unidos (SABATIER, 1991).

${ }^{5}$ Sobre estas duas vertentes, ver também análise crítica da produção acadêmica francesa na área urbana, desenvolvida por Topalov na década de 80 (TOPALOV, 1988)
} 
local de governo no Brasil, nas últimas décadas (JACOBI et alii, no prelo). Este movimento de inovação envolve dois aspectos: a ampliação do campo de ação dos governos locais e mudanças no conteúdo das políticas públicas e nos processos que presidem a formulação,a implementação e o controle de políticas e programas governamentais. Assim, pode-se dizer que os governos locais passaram não apenas a "fazer mais"; ao assumirem crescentes responsabilidades e atribuições, os governos locais também estão “fazendo diferente”.

A análise de políticas e programas inovadores desenvolvidos por governos municipais nas últimas décadas permite apreender este movimento de inovação, identificando, de um lado, novos campos de ação de governos locais, e, de outro inovações nos conteúdos das políticas públicas e nos processos pelos quais estas ações são efetivadas. As políticas públicas e os programas governamentais efetivamente implantados, ao serem apontados como inovadores pelos próprios governantes ou por outros atores governamentais, tendem a indicar novos temas da agenda “de decisão”, segundo a conceituação de Kingdon, isto é, tendem a indicar a incorporação pela ação governamental de novos temas, sejam estes referentes a "novas políticas” ou a "novos processos”.

Com base em banco de dados reunido pelo Programa Gestão Pública e Cidadania desde $1996^{6}$, num total de mais de 3500 iniciativas de governos municipais ${ }^{7}$, identificam-se a seguir tendências de inovação na ação local, em torno dos dois eixos mencionados anteriormente. Procura-se, ao mesmo tempo, apontar para temas de pesquisa associados a tais inovações.

\section{Ampliação do campo de ação dos governos locais e a reformulação no conteúdo de políticas públicas}

Dentre as iniciativas de governos municipais inscritas no Programa Gestão Pública e Cidadania, destacam-se políticas e programas das áreas de educação, crianças e adolescentes e saúde, representando, respectivamente, 16\%, 16\% e 13\% dos casos. Estas são áreas em que tem ocorrido um processo de transferência de atribuições para a esfera

\footnotetext{
${ }^{6}$ Programa de identificação, premiação e disseminação de iniciativas inovadoras de governos subnacionais, desenvolvido pela Fundação Getulio Vargas de São Paulo (FGV-EAESP) e pela Fundação Ford, com apoio do BNDES.

${ }^{7} \mathrm{O}$ banco de dados reúne mais de 5000 programas, dos quais cerca de 70\% são municipais.
} 
municipal de governo, sob influência de legislação, de diretrizes e de normas federais, configurando novos desafios para este nível de governo.

Há outros temas substantivos que também se destacam, como gênero, terceira idade, desenvolvimento local, geração de emprego e renda, crédito ao pequeno produtor (incluindo o pequeno produtor rural), questão ambiental - com destaque para a gestão de recursos hídricos e de resíduos sólidos - e finanças públicas locais (aumento da arrecadação e racionalização de gastos). Tais áreas de ação, a exemplo das anteriores, passaram a fazer parte da agenda governamental "local” no Brasil.

A inclusão destes novos campos de ação à agenda local envolve não apenas uma ampliação da esfera de atuação dos governos municipais, mas também, em parte significativa das políticas, uma redefinição do conteúdo das próprias políticas (FARAH, 2000 e FARAH, 2001). Em diversos setores, a ação inovadora corresponde à incorporação da perspectiva de direitos, em contraposição seja a uma abordagem paternalista, baseada na tutela e na concessão, seja a uma abordagem repressiva (como a adotada até então no tratamento de adolescentes infratores), seja à exclusão do acesso a serviços a determinados segmentos da população.

A perspectiva de direitos fica clara quando se consideram políticas e programas dirigidos a alguns segmentos da população. Iniciativas dirigidas à Terceira Idade procuram integrar socialmente os idosos, articulando a programas de setores específicos, sobretudo da área da saúde, atividades complementares que possibilitem o resgate de sua auto-estima. O atendimento de portadores de sofrimento físico e mental inclui ações voltadas à "humanização” do tratamento prestado na área de saúde e à integração social do portador de deficiência.

Na incorporação da perspectiva de gênero por políticas e programas de gênero também está presente a noção de direitos, em áreas como combate à violência contra a mulher, saúde, capacitação e geração de emprego e renda (FARAH, 1999 e FARAH, 2001).

As políticas e programas voltados a crianças e adolescentes, por sua vez, têm como foco a reinserção social de crianças e adolescentes em situação de risco pessoal ou social, com base na noção de direitos, tendo como referência o E.C.A. - Estatuto da Criança e do Adolescente - de 1990, caracterizando uma ruptura com relação às políticas dirigidas ao “menor”, de caráter assistencialista-repressivo (FERRAREZI, 1995). 
Uma nova abordagem das políticas públicas também preside as ações nas áreas de educação e saúde. Nas políticas e programas educacionais, embora haja ainda o desafio da universalização, o objetivo principal é o combate à evasão e à repetência. Na saúde, adotase uma abordagem preventiva, em oposição ao padrão curativo existente no setor. O atendimento diferenciado da comunidade indígena, em programas municipais destas duas áreas configura uma importante mudança em relação ao sistema de políticas sociais prevalecente por muitos anos no país, ao romper com a adoção centralizada de modelos padronizados, impermeáveis às características heterogêneas da população brasileira. Tais programas procuram adequar diretrizes gerais de suas respectivas áreas às especificidades da comunidade indígena, o que significa respeitar suas tradições, tanto no que se refere ao cuidado com a saúde, como no resgate das línguas indígenas, durante o processo educacional.

O que estas novas políticas - novas enquanto campos e novas enquanto conteúdo e abordagens - trazem como desafios para a pesquisa? Que temas de investigação emergem desta “nova” realidade local?

Um primeiro conjunto de temas coincide com as próprias novas áreas de atuação governamental. Trata-se inicialmente de caracterizar o que está sendo feito, em descrever em que consistem as novas políticas em áreas como gênero, educação, saúde, crianças e adolescentes, gestão de recursos hídricos, desenvolvimento local, geração de emprego e renda, apoio ao pequeno produtor (crédito e capacitação), gestão de resíduos sólidos, dentre outras que têm se constituído como áreas relevantes de ação de governos locais.

Estes itens constituem temas relevantes de investigação que emergem da ação concreta dos governos locais nas últimas décadas, alguns dos quais já presentes na produção recente sobre governos locais. Assim, por exemplo, têm sido desenvolvidas pesquisas sobre programas de saúde da família; sobre o Programa de Erradicação do Trabalho Infantil; sobre o impacto de iniciativas federais como o FUNDEF - Fundo Nacional de Desenvolvimento da Educação Fundamental - sobre políticas municipais, sobre programas de desenvolvimento local e ainda sobre iniciativas na área de finanças públicas municipais. Tais estudos constituem em sua maior parte estudos de caso, contribuindo para que se conheça “de dentro” alguns programas e que se avance na produção de um conhecimento 
especializado setorial, dando continuidade a um processo iniciado em períodos anteriores (MELO, 2000).

Menos freqüentes são estudos mais abrangentes, que considerem um conjunto ampliado de programas. Tal é o caso, por exemplo de estudo desenvolvido por Farah sobre tendências gerais e fatores explicativos da inclusão do tema "gênero" no campo de ação local, (FARAH, 1999 e FARAH, 2001), e de trabalho de Arretche sobre os fatores que explicam a variação da descentralização de políticas sociais, segundo regiões e setores distintos (ARRETCHE, 2000).

As pesquisas sobre estes novos campos de atuação e sobre estas novas abordagens incluem, dentre outras, as seguintes dimensões:

1. Identificação de novos campos de ação dos governos locais ${ }^{8}$;

2. Análise de inflexões em conteúdos e abordagens das políticas públicas desenvolvidas localmente em relação a políticas públicas características do período Nacional-Desenvolvimentista, marcado por um federalismo centralizado;

3. Caracterização do que está sendo feito em cada área de intervenção governamental e do modo (como) de implementação das novas políticas ou programas;

4. Análise dos fatores que condicionam e explicam as mudanças em cada setor e dos fatores comuns que explicam variações em diversos setores;

5. Identificação dos processos políticos e dos atores envolvidos na inclusão destes novos temas na agenda governamental e de decisão "local";

6. Análise da contribuição de diferentes fatores para o desenvolvimento da política ou programa: capacitação da burocracia local, disponibilidade de recursos financeiros, características da estrutura de dominação política local, características das organizações estatais, capital social etc...

7. Pesquisa setorial comparada entre diferentes regiões, estados e localidades, visando explicar a variação entre diferentes locais (entre características dos programas e seus resultados);

${ }^{8}$ Para o que o próprio banco de dados do programa Gestão Pública e Cidadania constitui uma fonte de dados 
8. Pesquisa comparada intersetorial;

9. Análise de relações intergovernamentais verticais, visando identificar a contribuição dos níveis mais abrangentes de governo para o desenvolvimento das políticas e programas, o grau de autonomia municipal, assim como as dificuldades que caracterizam estas relações;

10. Avaliação de políticas e programas, incluindo a identificação de principais "gargalos” em cada setor;

11. Estudo do processo de disseminação de inovações e políticas públicas;

12. Pesquisa sobre a continuidade de políticas e programas inovadores;

13. Análise da articulação de programas em políticas setoriais locais;

14. Análise sobre a articulação de programas com projetos governamentais mais abrangentes;

15. Identificação de novos temas e questões incorporados à agenda pública.

Este conjunto de itens inclui temas de investigação e abordagens analíticas diversas que podem ser articulados em pesquisas concretas. Cada um dos itens e, em alguns casos, alguns subitens podem, por outro lado, constituir por si só o objeto de uma ou mais pesquisas e mesmo de um programa de pesquisa, como por exemplo no caso de estudos comparados sobre a influência da capacitação da burocracia local sobre o desenvolvimento de determinada política.

Não será possível, no âmbito deste trabalho, discutir cada um destes aspectos. Como especial desafio, destaca-se o relativo à avaliação de políticas e programas e à definição de metodologias de avaliação flexíveis e dinâmicas.

A avaliação de políticas e programas já foi incorporada à “agenda de pesquisa” do campo de estudos de governo local. Gostaria, não obstante, de destacar alguns pontos em relação a esta temática. A avaliação de uma determinada iniciativa ou conjunto de iniciativas não deve estar voltada apenas para uma avaliação operacional de cada iniciativa, como forma de subsidiar decisões relativas à continuidade de programas, mas deve também estar “conectada” com o processo de redefinição das questões que passam a compor a "agenda pública” (ou, mesmo antes, a agenda de atores “críticos” a determinado campo).

CADERNOS GESTÃO PÚBLICA E CIDADANIA, V. 11, N. 48 - JAN/JUNHO 2006 
Assim, por exemplo, na área de gênero, no que se refere à violência contra a mulher, a criação de Delegacias de Defesa da Mulher passou a fazer parte da agenda governamental já há mais de uma década. A avaliação de uma iniciativa local com esta característica hoje, no entanto, não será completa se não estiver atenta para a dinâmica da própria agenda dos movimentos de mulheres, que ampliaram o leque de “alternativas de ação” neste campo, levando a uma revisão da agenda pública, que hoje inclui também como prioridades a implantação de casas abrigo e a articulação de medidas de apoio às vítimas à revisão das penas atribuídas aos que cometem violência contra a mulher.

Na análise de políticas e programas é importante incorporar, por outro lado, uma perspectiva de problematização permanente que permita - uma vez reconhecidas as inovações e os “avanços” - identificar “quais os obstáculos e problemas principais enfrentados pela política ou programa”. Nesta perspectiva de problematização, outra dimensão da análise consiste em uma avaliação centrada na incorporação efetiva pelas iniciativas de uma nova abordagem ou perspectiva: o quanto políticas e programas que se apresentam como inovadores do ponto de vista de sua concepção, estão conseguindo de fato mudar a concepção que preside a política na prática?

Assim, por exemplo:

a. Está ocorrendo uma ruptura da padronização, com a incorporação da diversidade do público-beneficiário no planejamento e na implementação das ações?

b. A ação local está sendo capaz de romper com a padronização e uniformidade que não reconhecia diversidades regionais e locais?

c. Os programas que se dizem adeptos de uma “perspectiva de direitos” - em áreas como crianças e adolescentes, saúde, terceira idade, geração de emprego e renda, dentre outras - estão na prática adotando esta orientação?

Outro desafio diz respeito à análise de mudanças mais abrangentes, que transcendam políticas e programas isolados. As políticas e programas inovadores destacam-se no quadro da ação local, em primeiro lugar, como visto, por constituírem novos campos de atuação governamental ou por adotarem novas abordagens. Um eixo relevante de pesquisa consiste na análise da ocorrência de mudanças de maior abrangência, que transcendam políticas e 
programas isolados, afetando a cultura política local. Assim, questões como a se seguem são também relevantes:

a. A condução de políticas públicas a partir da perspectiva de direitos, de abordagens preventivas e do reconhecimento da diversidade passou a fazer parte da cultura política de determinado município?

b. O que explica a diferença entre municípios quanto a este aspecto? Que fatores contribuem para mudanças duradouras neste sentido?

Dificilmente se pode dissociar a reflexão sobre cada dos novos campos de atuação dos governos locais de análises relativas a mudanças nas instituições e nos processos políticos e de gestão neste nível de governo. Isto remete ao segundo eixo de transformações na ação dos governos locais ocorridas nas últimas décadas.

\section{Novas instituições e novas práticas}

A incorporação do tema da inovação pelo debate sobre governos locais no Brasil se deu associada a duas temáticas centrais: a da democratização e a da eficiência. Nos dois casos, enfatizam-se instituições e processos. De um lado, a inovação é associada à criação de mecanismos institucionais que favoreçam a inclusão da sociedade civil no processo decisório, seu envolvimento na implementação e no controle das políticas públicas, garantindo a democratização do "Estado em ação", e transparência e accountability à ação estatal. De outro lado, a inovação é associada a mudanças em instituições e práticas, que garantam eficiência à ação estatal, via agilização de procedimentos, combate à corrupção (e transparência), controle por agentes externos ao aparelho estatal (accountability); capacitação da burocracia, incorporação de novas tecnologias, dentre outras medidas.

Várias das políticas e programas desenvolvidos por governos locais nas últimas décadas no Brasil envolvem esse processo de construção institucional e de criação de novas práticas políticas e de gestão que apontam na direção da democratização e de uma maior eficiência das políticas públicas e da gestão local.

Dentre estas inovações, destacam-se as relativas à construção de uma nova governança no nível local de governo, caracterizada pela inclusão de novos atores no processo de formulação, implementação e controle de políticas públicas. É possível identificar alguns

CADERNOS GESTÃo PÚBLICA E CIDADANIA, V. 11, N. 48 - JAN/JUNHO 2006 
eixos em torno dos quais esta nova governança se estrutura, configurando novos arranjos institucionais que conformam novas práticas de governo e de gestão:

- Criação de mecanismos institucionais de participação da sociedade civil: conselhos, orçamento participativo e administração participativa;

- Parcerias para a provisão de serviços públicos;

- Abordagem integral e articulação intersetorial

- Colaboração intergovernamental "horizontal”: os consórcios intermunicipais

- Redes

\section{Criação de mecanismos institucionais de participação}

Muitas das políticas e dos programas de governos locais desenvolvidos no período recente têm como um de seus elementos centrais a participação dos cidadãos na formulação, na implementação e no controle de políticas públicas, sobretudo das políticas sociais, assinalando uma ruptura com o período anterior, marcado pela exclusão da sociedade civil dos processos decisórios. Para viabilizar esta participação, desde o início da década de 80, novos canais institucionais vêm sendo implantados no nível local de governo, destacandose os conselhos de políticas públicas e o orçamento participativo.

Atualmente, há no Brasil conselhos de políticas públicas em diversas áreas de ação dos governos locais, como saúde, educação, trabalho e emprego, meio ambiente, planejamento e gestão urbana, direitos da criança e do adolescente, do negro, da mulher, dentre outros. Em parte significativa dos casos, estes canais são criados localmente por força de legislação federal. A influência federal também se faz sentir pelo condicionamento do acesso a recursos e fundos à criação de conselhos locais. O orçamento participativo, por sua vez, surgiu como criação local e se difundiu "horizontalmente" estando hoje presente como mecanismo de participação popular em mais de uma centena de municípios. Em algumas localidades, a “filosofia” da participação que preside o orçamento participativo se expandiu, configurando estratégias mais abrangentes de “administração participativa”, na qual o plano de desenvolvimento local e o planejamento anual envolvem a participação da sociedade civil. 
Esta primeira frente de inovação nas instituições e processos políticos e de gestão constitui um campo temático de investigação, no âmbito do qual já se têm desenvolvido diversas pesquisas, em geral consistindo em estudos de caso referentes a experiências singulares. Este campo temático ainda requer, no entanto, o desenvolvimento de novas pesquisas, sobretudo de pesquisas comparadas, que permitam uma reflexão de maior abrangência teórica, derivadas da comparação de diversos casos e situações. Dentre as questões a serem aprofundadas incluem-se:

a. Composição dos conselhos - critérios, variação setorial e local, representatividade formal e "de fato"; inclusão efetiva de novos segmentos ao processo decisório e “extensão” desta inclusão; capacitação política e técnica;

b. Natureza dos conselhos (deliberativo, consultivo) e fatores que explicam seu caráter;

c. Relação entre conselhos e poder executivo (cargos eletivos e burocracia setorial) e legislativo;

d. Relação dos conselhos com a estrutura de dominação local;

e. Efetividade dos conselhos em relação a seus objetivos e fatores que explicam seu sucesso ou eventual "esvaziamento": (os conselhos têm funcionado de fato como espaço de ampliação da participação e do controle e contribuído para uma maior transparência e, accountability das ações estatais) ?

f. Relação dos conselhos com a eventual constituição de uma estrutura de governança local - envolvendo um conjunto de instituições governamentais e não-governamentais;

g. Variação setorial e regional do perfil e do desempenho dos conselhos e fatores que explicam esta variação (legislação e incentivos federais e estaduais, movimentos sociais setoriais e locais, dentre outros);

h. Principais desafios - obstáculos e problemas.

A exemplo das observações feitas anteriormente em relação à análise de políticas e programas, é importante aqui também haver não apenas estudos “de caso” sobre conselhos setoriais, em determinada localidade, mas também se desenvolver uma reflexão mais abrangente, com base na comparação intersetorial e entre diferentes municípios, buscando 
identificar fatores que explicam “sucessos” e “fracassos”, sejam estes fatores ligados a instituições políticas, novas ou pré-existentes, à existência de capital social, à burocracia local, a partidos políticos e à estrutura de dominação política local, dentre outros fatores.

O mesmo tipo de questões pode orientar estudos sobre o orçamento participativo, destacando-se aqui também a necessidade de estudos comparados.

Em ambos os casos, a perspectiva da avaliação deve estar presente, enquanto problematização das inovações: quais os principais problemas enfrentados para que se atinjam os objetivos de democratização do processo decisório e de implementação?

\section{Parcerias para a provisão de serviços públicos}

A inclusão de novos atores no processo de implementação de políticas públicas significa ainda um outro tipo de inovação: o estabelecimento de parcerias com organizações nãogovernamentais (ONG), com o setor privado e com a própria comunidade, tendo em vista a provisão de serviços públicos. A execução de programas e a gestão de equipamentos e serviços públicos são, neste caso, transferidas para entidades não-estatais, envolvendo privatização, terceirização ou outras modalidades de vínculos entre o município e segmentos não-governamentais.

Nos programas municipais considerados inovadores pelos responsáveis por sua implementação, numa perspectiva de gestão pública “com” cidadania, tende a ocorrer sobretudo parcerias com ONG e com a comunidade, para a gestão de equipamentos e de serviços, o que ocorre na área de saúde e de educação, para citar alguns exemplos (FARAH, 2001). Menos freqüentes no conjunto de programas analisados são as iniciativas de privatização de serviços.

No âmbito do campo de estudos de governo local, as experiências de privatização têm recebido maior atenção, em detrimento das que envolvem associação com ONG ou entidades da sociedade civil para provisão de serviços. Constituem exceção estudos recentes sobre o envolvimento de cooperativa de catadores de papel por governos locais no âmbito de sistemas municipais de coleta e tratamento de lixo, como mecanismo de inclusão social. A análise da articulação entre governo e sociedade civil na provisão de serviços constitui, entretanto, uma frente que merece atenção, tanto para registro do que 
efetivamente está ocorrendo (inclusive para se estimar o quanto este tipo de associação público-privado vem se dando no nível local de governo), como para análise de suas características e dos fatores que explicam seu eventual "sucesso" e principais dificuldades.

\section{Abordagem integral e articulação intersetorial}

A inclusão de novos atores no processo de formulação e implementação de políticas públicas tem significado também a ruptura do modelo baseado na centralização de decisões em uma única agência estatal e na atuação setorial, pelo envolvimento de várias instituições estatais, de diferentes níveis de governo, na promoção de programas e políticas.

Uma inovação neste sentido consiste na promoção de ações integradas. Por meio da focalização de um segmento da população ou de uma área de intervenção, procura-se formular políticas integrais, articulando ações em geral fragmentadas e dispersas. Isto ocorre tanto pela incorporação de uma abordagem setorial, como pela colaboração de diferentes agências estatais de um mesmo setor. Diversos programas adotam este enfoque, tais como programas para crianças e adolescentes em situação de risco social e programas com foco na mulher, sobretudo os que combatem a violência contra a mulher. Procura-se prestar um atendimento integral à clientela atendida, coordenando ações das áreas de saúde, educação, assistência jurídica, formação profissional etc. A abordagem integral está presente também em programas da área de habitação e desenvolvimento urbano, que, além das ações específicas nestas áreas, incluem intervenções nas áreas de educação, saúde e geração de emprego e renda.

A abordagem integral, envolvendo coordenação de diversas ações, de diferentes agências governamentais e a articulação intersetorial é, no entanto, ainda hoje, bastante incipiente. A inexistência de coordenação e de intersetorialidade tem sido apontada freqüentemente como um obstáculo à eficiência e à efetividade das políticas públicas e como um resultado de práticas de gestão pública marcadas pelo clientelismo.

A defesa da necessidade de coordenação e de intersetorialidade numa perspectiva normativa não tem tido contrapartida no desenvolvimento de pesquisas sobre estes temas. Dentre as questões que merecem investigação neste sentido, incluem-se: 
a. Identificação de políticas e programas em que ocorre abordagem integral, cooperação entre agências de um mesmo setor, intersetorialidade e coordenação de ações e programas;

b. Fatores que explicam a adoção deste tipo de estratégia;

c. Fatores que dificultam este tipo de estratégia;

d. Estudos comparativos entre iniciativas “integradoras” e "setoriais”.

\section{Colaboração intergovernamental “horizontal”: os consórcios intermunicipais}

Dentre os novos arranjos institucionais que emergiram no período recente no país, destacam-se os consórcios intermunicipais. Por meio dos consórcios, municipalidades vizinhas se articulam para enfrentar em conjunto problemas cuja superação ultrapassa a capacidade de um único município. Estabelece-se uma gestão de políticas públicas de base microrregional, que possibilita a ampliação da oferta de serviços e a viabilização de soluções que, isoladamente, cada municipalidade não seria capaz de implementar (CRUZ, 2002). Os consórcios têm se difundido sobretudo nas áreas de saúde e de meio ambiente: no primeiro caso, a colaboração intermunicipal constitui um dos elementos centrais da implantação de um sistema de saúde integrado e hierarquizado, voltado para a universalização do acesso e para a efetividade dos serviços; no segundo caso, desde as primeiras ações na área ambiental, evidenciou-se a necessidade de uma articulação de esforços, uma vez que os problemas não se circunscrevem a fronteiras políticoadministrativas.

Os consórcios e outros fóruns de discussão e deliberação regional estabelecidos entre municípios no período recente constituem um tema de grande relevância no campo de estudos de governo local, o qual tem sido objeto de análise por alguns estudos, em sua maior parte, estudos de caso setoriais ${ }^{9}$. O desafio em termos de pesquisa ainda é considerável, no entanto, sendo necessários tanto estudos setoriais, como de abrangência maior, que discutam tanto aspectos organizacionais deste novo mecanismo de gestão, como suas implicações político-institucionais.

\footnotetext{
${ }^{9}$ Constitui uma das poucas exceções estudo de Cruz, em que se faz um balanço dos consórcios existentes no país (CRUZ, 2002).
} 
Dentre as questões relevantes sobre consórcios, podem ser mencionadas:

a. Características institucionais: composição, regras de funcionamento, recursos previstos, objetivos, etc.;

b. Papel da liderança;

c. Tipo de questão discutida e deliberada;

d. Capacidade efetiva de mobilizar recursos e de "promover" políticas, programas e ações;

e. Relação com governos locais e estaduais;

f. Relação com estrutura de dominação local;

g. Incentivos federais e estaduais à criação de consórcios;

h. Variação setorial e regional e fatores responsáveis por esta variação;

i. Avanços e dificuldades principais.

\section{Redes}

Algumas iniciativas implementadas pelas esferas locais de governo configuram redes de atores e de entidades, mobilizados em torno de um ou mais problemas de interesse público, cujo enfrentamento ultrapassa a capacidade de ação isolada do Estado, seja por limites financeiros, seja pelo maior grau de imersão no problema que uma ação coordenada permite.

A articulação em rede constitui uma inovação em relação ao modelo centrado em uma única agência estatal, assim como em relação ao processo que excluía a sociedade civil das decisões. Assim, estão representadas nas redes a sociedade civil - por meio de ONG e das mais diversas formas de representações da comunidade - e diferentes níveis de governo, assim como mais de um governo de mesmo nível.

O estudo sobre redes tem se expandido na área de administração, sendo, no entanto, menos presentes em análises relativas a governos locais. Questões similares às indicadas para o estudo de consórcios cabem no estudo de redes. 


\section{Temas transversais}

Considerando as diversas modalidades de arranjos institucionais que emergiram nas últimas décadas, referidos nesta seção, é possível ainda identificar algumas questões de ordem geral, que configuram temas de investigação transversais, e que podem ser sintetizados nas seguintes questões:

a. Os novos arranjos institucionais contribuem para a efetivação dos objetivos de democratização e de eficiência?

b. Estes novos mecanismos estão contribuindo para a promoção de maior transparência e para garantia de accountability no nível local de governo?

Até este momento, foram identificados temas e questões de investigação relevantes para o campo de estudos de governo local, a partir da agenda de decisão, isto é, a partir da análise do que os governos têm feito, de políticas e programas desenvolvidos por governos locais.

Mas é possível também identificar algumas ausências relevantes (ou presenças ainda incipientes) na ação de governos locais hoje no Brasil. Trata-se de temas já presentes na agenda pública ou sistêmica, isto é, que já fazem parte da preocupação “do país” (nos termos de Kingdon), estando em alguns casos em processo de incorporação pela agenda governamental e de decisão e, em outros, ainda fora da agenda governamental. Trata-se, em ambos os casos, de temas emergentes na agenda política e que configuram também temas emergentes potenciais para o campo de estudos de governos locais.

Dentre estes temas, destacam-se políticas para a juventude e políticas com enfoque étnico e racial. No primeiro caso, já se faz sentir a presença do tema na agenda governamental e as primeiras manifestações de incorporação do tema pela agenda de decisão de governos locais. No caso de políticas com recorte de raça, no nível local de governo, em que pese o debate recente sobre a política de cotas para acesso à universidade, a incorporação do tema pela agenda governamental de governos locais é ainda muito incipiente. O desenvolvimento de pesquisas sobre estes dois temas constitui frente relevante, podendo contribuir para, sobretudo no caso da questão racial, a inclusão na agenda governamental (e de pesquisa) de uma questão até então “invisível”.

É também notável a ausência de iniciativas inovadoras centradas no Poder Legislativo ou articuladas explicitamente a este poder, no nível local de governo. A tradição brasileira de 
identificação do Estado ao poder executivo se faz sentir também no nível local e no próprio movimento de inovação na gestão pública. Este constitui outro desafio para a pesquisa: pensar (repensar) o Legislativo no nível local de governo e sua articulação com o processo de construção de uma governança democrática e de uma gestão pública local mais eficiente. Finalmente, o próprio movimento de inovação constitui tema de reflexão. Embora este termo venha sendo utilizado de forma bastante freqüente na referência às mudanças em curso no nível local de governo nas últimas décadas, ainda é relativamente recente o esforço de reflexão sobre este processo e sobre o conceito de inovação na área pública e sua “aplicação” a iniciativas de governos locais (JACOBI e PINHO, 2006). Temática complementar diz respeito à disseminação das iniciativas inovadoras de governos locais; processo pouco estudado na área pública, mas de grande relevância no Brasil contemporâneo em que iniciativas que se desenvolvem ou se consolidam localmente têm se difundido para outras localidades. Entender este processo constitui ainda um tema pouco estudado (PAULICS, 2003; WRAMPLER, 2004, SUGYAMA, 2004 e 2006; FARAH, 2006 a, b e c; MELO, 2004).

\section{Conclusão}

A agenda de pesquisas sobre governo local é influenciada pela evolução temática e pelo debate teórico próprios às disciplinas que contribuem para este campo de estudos. Mas os temas de pesquisa também refletem e incorporam a agenda política que se configurou em torno deste campo, assim como a dinâmica desta agenda. A agenda governamental e a agenda de decisão dos governos locais no Brasil no período recente passaram a incluir novos temas - novos campos de intervenção de governos locais, novas abordagens na promoção das políticas públicas e novos processos de formulação e implementação de políticas e programas.

Tais temas configuram novos temas de pesquisa, alguns dos quais já incorporados pela literatura, outros ainda pouco explorados, os quais se procurou identificar no presente trabalho, a partir da análise da experiência recente de governos municipais no Brasil. Além dos temas associados à ação governamental e aos desafios enfrentados por esta ação, há, no entanto, temas emergentes - já incorporados à agenda pública - mas ainda não integrados pela ação estatal. Trata-se de questões que já constituem objeto de preocupação 
pública - seja de um conjunto ampliado de atores, seja de algum grupo ou segmento que participa da disputa para influenciar a agenda governamental. O trabalho também identificou alguns destes temas que, embora integrem a agenda pública, estão ausentes da ação governamental local ou ainda são incipientes, tais como juventude, etnia e Poder Legislativo municipal.

\section{Bibliografia}

ARRECHE, Marta. Estado federativo e políticas sociais: determinantes da descentralização. Rio de Janeiro: Revan; São Paulo, FAPESP, 2000.

CRUZ, Maria do Carmo Toledo.Consórcios intermunicipais: uma alternativa de integração regional ascendente. In: SPINK, Peter, CACCIA-BAVA, Silvio e PAULICS, Veronika. Novos contornos da gestão local: conceitos em construção. São Paulo: ócus/Programa Gestão Pública e Cidadania, FGV-EAESP, 2002.CRUZ, 2002

FARAH, Marta Ferreira Santos. Disseminação de Políticas Públicas e Programas Governamentais no Nível Subnacional de Governo. In: Anais do X Colóquio Internacional de Poder Local: Desenvolvimento e gestão social de territórios. Salvador, BA, 11 a 13 de dezembro de 2006. Salvador, CIAGS/UFBA, 2006. 12 páginas. CD-ROM. Disponível também no site da ANPAD, para associados (www.anpad.org.br) 2006 a

FARAH, Marta Ferreira Santos. Dissemination of Innovations: Learning from sub-national awards programmes in Brazil. In: UNDESA. Innovations in Governance and Public Administration: replicating what works. United Nations. Department of Economic and Social Affairs. New York, 2006 (Adriana Alberti and Guido Bertucci (org.). 2006 b

FARAH, Marta Ferreira Santos. Dissemination of local programs and policies in Brazil: the contribution of the Public Management and Citizenship Program. Paper delivered at the 2006 Meeting of the Latin American Studies Association. San Juan, Puerto Rico, March 15-18, 2006. 2006 c

FARAH, Marta Ferreira Santos. Gênero e políticas públicas na esfera local de governo. Organizações e Sociedade, v.6, n. 14, p.65-104, jan.abr.1999.

FARAH, Marta Ferreira Santos. Governo local, políticas públicas e novas formas de gestão pública no Brasil. Organizações e Sociedade, v.7, n.17, p 59-86, janeiro/abril 2000.

FARAH, Marta Ferreira Santos. Parcerias, novos arranjos institucionais e políticas públicas no nível local de governo. Revista de Administração Pública. V.35, n. 1, p. 119-144. Rio de Janeiro, jan./fev. 2001.

FERRAREZI, Elisabete Roseli. Evolução das políticas dirigidas à infância e à adolescência: a Secretaria do Menor São Paulo e a introdução de um novo paradigma. São Paulo, 1995 (Dissertação de Mestrado em Administração Pública, defendida junto ao Curso de Mestrado em Administração Pública e Governo da FGV-EAESP) 
FUKS, Mario. Definição da agenda, debate público e problemas sociais: uma perspectiva argumentativa da dinâmica do conflito social. In: Bib,n.49, $1^{\circ}$ sem. 2000, p. 79-94.

JACOBI, Pedro e PINHO, José Antonio (org.). Inovação no campo da gestão pública local: novos desafios, novos patamares. Rio de Janeiro: Editora FGV, 2006. p. 41-77.

Kingdon, John W. Agendas, alternatives, and public policies. New York: HarperCollins, 1995. 2nd ed.

MELO, Marcus André. Escolha institucional e a difusão dos paradigmas de política: o Brasil e a segunda onda de reformas previdenciárias. Dados, v. 47, n. 1, 2004, Rio de Janeiro.

MELO, Marcus André. Estado, Governo e Políticas Públicas”. In: MICELI, S. (Org.). O Que Ler na Ciência Social Brasileira (1970-1995). Ciência Polítia, Vol.III. São Paulo, Ed. Sumaré, Brasília, ANPOCS \& CAPES, pp.59-100, 2000.

PAULICS, Veronika Anna Theodora. Disseminação do programa de garantia de renda mínima no Brasil (1991-1997).São Paulo, FGV-EAESP, 2003 (Dissertação de mestrado em Administração Pública e Governo). Texto digitado.

PINHO, José Antonio Gomes de e SANTANA, Mercejane Wanderley. Inovação na gestão pública no Brasil: uma aproximação teórico-conceitual. Trabalho apresentado no 22 ENANPAD - Encontro Anual da ANPAD. Foz do Iguaçu, PR, 27 a 30 de setembro de 1998. Texto digitado.

SABATIER, Paul A., JENKINS-SMITH, Hank C. and STEWARD, Jr., Joseph. .Toward Better Theories of the Policy Process (Symposum). PS: Political Science and Politics, v.24, n.2, June 1991.

SPINK, Peter. Avaliação democrática: propostas e práticas. Rio de Janeiro, Associação Brasileira Interdisciplinar de AIDS, 2001 (Coleção ABIA, Fundamentos de Avaliação, n.3.

SPINK, Peter. The rights approach to local public management: experiences from Brazil. ERA. Revista de Administração, v.40, n.3, p.45-65, jul./set.2000.

SUGIYAMA, Natasha Borges. Political incentives, ideology and social networks: the diffusion of social policy in Brazil. Paper delivered at the 2004 Meeting of the Latin American Studies Association. Las Vegas, Nevada, October7-9, 2004.

SUGIYAMA, Natasha Borges.Ideology and networks: social policy diffusion in decentralized Brazil. Paper delivered at the 2006 Meeting of the Latin American Studies Association. San Juan, Puerto Rico, March 15-18, 2006.

TOPALOV, Christian. Fazer a história da pesquisa urbana: a experiência francesa desde 1965. Espaço e Debates, ano VIII, n. 23, p. 5-31, 1988. 
WAMPLER, Brian. The diffusion of participatory budgeting in Brazil. Paper delivered to Lasa 2004 - Latin American Studies Association Meeting, Las Vegas, Nevada, October 7-9 2004. (Draft version)

Artigo recebido em : 25/04 de 2005 e aprovado em 28/07 /2005. 